\title{
CARDIOVASCULAR RESPONSES OF TYPE 2 DIABETES PATIENTS TO INTERMITTENT AND CONTINUOUS AEROBICS EXERCISES
}

\author{
MO Akindele, Kodzo Philip and Mustapha Naimat \\ Department of Physiotherapy, Faculty of Medicine, Bayero University, Kano, Kano State \\ Corresponding Author \\ O Akindele \\ Email:mukaakin@yahoo.com
}

\begin{abstract}
SUMMARY
Background: The use of aerobic exercise as a form of glycemic control in type 2 diabetes mellitus has been well documented in the literatures. High blood pressure has been shown to be one of the sequelae of type 2 diabetes mellitus. Determination of mode of exercises for glycemic control that will not adversely affect the cardiovascular indices of type 2 diabetes mellitus subjects is highly indicated.

Objective: The purpose of this study was to determine the acute cardiovascular responses of type 2 diabetes mellitus subjects to continuous and intermittent modes of exercises.

Results: There was statistical significant difference in heart rate of both groups. Continuous mode of exercise elicited no statistical difference in SBP and DBP but there was statistical significant difference in SBP in intermittent exercise group with no statistical significant in their DBP. Cross comparison of pre and post cardiovascular indices showed that there were statistical significant differences in SBP $(F=0.710, \quad P>0.05)$ and DBP $(F=1.397$, $\mathrm{P}>0.05)$.

Conclusion: Cardiovascular responses of type 2 diabetes mellitus subjects were higher in intermittent exercise group compared with the continuous exercise group.
\end{abstract}

KEYWORDS: Type 2 diabetes mellitus, Aerobic exercise, cardiovascular response.

\section{INTRODUCTION}

Diabetes Mellitus (DM) is a common and under diagnosed disease that describes a group of disorders in which there is breakdown of normal mechanism which keeps the blood glucose at a normal level. It was recognized as early as 1500 BC by an ancient Egyptian Physician who described it as a disease associated with the passage of much urine (polyuria) (CDA,2006). It is a clinical syndrome characterized by hyperglycemia due to absolute or relative deficiency or diminished effectiveness of insulin, which affects the metabolism of carbohydrates, proteins and fat, thus causing a significant disturbance of water and electrolyte balance (Cotran et al, 1999; Haslet et al 2002).

The committee on the Diagnosis and Classification of Diabetes Mellitus revised and classified DM, based on etiology and pathogenesis rather than modalities of treatment, into Type 1, Type 2, gestational and other specific type which includes diabetes due specific genetic effects, medications and other diseases(Expert Committee,1997). In Type 1, there is inability of the pancreas to produce sufficient insulin because of failure of B-cells in the pancreas while Type 2 is due to ineffectiveness of insulin to facilitate transport of glucose across the cells because of insulin resistant (Wilmore and Costill, 2004). Both genetic and environmental factors have been implicated in the etiology of type 2 DM though the exact genetic defects are not currently well defined (Hickey et al, 1995).

World Health Organization WHO data in 2000 showed that approximately 177 million people had DM worldwide and it was postulated that this number might rise to 370 million by the year 2030 ( Prevalence of Diabetes, 2000). WHO, from the same report, said that a larger percentage of this increase will occur in developing countries, especially Africa, due to population growth, ageing, unhealthy diets, obesity and sedentary life styles. The approximate number of people with DM in Nigeria from WHO data in 2000 was estimated to $1,706,655$ and postulated that this figure may rise to 4,834,885 in the next ten decade.

Successful management of type-2 DM requires a multidimensional approach, which includes pharmacotherapy, diet therapy and exercise therapy. The immediate therapeutic goals are to stabilize blood sugar and eliminate the symptoms of high blood sugar while the long term goals are to relieve symptoms, prolong life and prevent long term complications such as 
heart disease, and kidney failure (Dunstan et al, 2001).

Exercise therapy is considered by many experts as one of the three cornerstones for optimal diabetes management because of its low cost, non-pharmacological nature and additional aerobic and cardiovascular benefits (Joslin et al, 1959; Erick and Dick, 1996; Ivy et al 1999 and Haslet et al, 2002). Type-2 DM has been reported to responds well to exercise. Membrane permeability to glucose improves with exercise, which decreases the individual insulin resistance, and increases insulin sensitivity but these effects dissipates within 72 hours (Wilmore and Costill, 2004). Canadian Diabetes Association (CDA) opined that people with type- 2 diabetes should accumulate at least 150 minutes of moderateintensity aerobic exercise each week, spread over 3 non-consecutive days of the week or should be encouraged to accumulate greater than 4hours of exercise per week (CDA, 2003).

In line with CDA report, American Diabetes Association (ADA) also recommended that physical activity/exercise regimens should be at an intensity of $50-80 \% \mathrm{VO}^{2} \mathrm{max}$, three to four times a week for 30-60 minutes a session (ADA, 2004)

The prevalence of both symptomatic and asymptomatic coronary artery disease (CAD) is higher in both type I and type-2 diabetes mellitus (Sigal et al, 2004) and DM is one of the risk factors for cardiovascular disease (CVD) (Wilmore and Costal, 2004). Therefore, patients with DM may also have an underlying CVD, which may be aggravated during rehabilitation of DM patients using therapeutic exercises. Hu et al (2001) reported on 5125 female nurses with type-2 diabetes who completed detailed health questionnaire every two years, of which 323 developed new CVD events over 14 years of follow-up. Most exercise training studies of patients with type-2 DM have focused on glycemic control and less on the effects of exercise on cardiovascular health, yet there are data from variety of studies that provide strong albeit not perfect evidence that exercise should be a standard care not only for glycemic control but also for improving the cardiovascular system in this group of patients (Defronzo and Ferannini, 1991; Stewart, 2002).

Various studies have been done predominantly on non-DM population on the effects of exercise training on blood pressure (Whelton et al, 2002; Leon and Sanchez, 2001; Kraus et al 2002). To the best of our knowledge no published work on the acute effects of different modes of exercise training on blood pressure in people with type-2 DM was found. Therefore, this study is aimed at assessing the acute cardiovascular responses of type-2 DM subjects to two different modes of therapeutic exercises (continuous and intermittent regimen).

\section{METHODS Subjects}

Twenty subjects (12 males and 8 females) participated in the study. The subjects were sought from the outpatient specialty clinic of Aminu Kano Teaching Hospital (AKTH) after the approval of the ethical committee of AKTH was given. The procedure of each type of exercise was explained to each subject and each subject signed an informed consent.

Subjects with diagnosed type-2 DM were recruited for the study. Subjects with musculoskeletal problems, diabetes complications, cardiac problems and those with blood pressure $>140 / 90$ were excluded from the study. Subjects who met the inclusion criteria were conveniently assigned to Intermittent Group and Continuous Group with a total of ten subjects in each group. Physical Activity Readiness Questionnaire (PAR Q) was administered to each subject before commencement of the exercise. Subjects who answered yes to any of the questions were excluded from the study.

\section{Procedures}

Height and weight of the subjects were measured using SECA (Body Guard Ergocycle 995, Germany) height and weight scale. A computerized bicycle ergometer, Body Guard Ergocycle 955, made in Norway, was used for intermittent and continuous exercises. The subjects' heart rates were monitored using stopwatch and stethoscope while the blood pressures were measured using Mercury sphygmomanometer and stethoscope.

Each subject resting hear rate (RHR), resting diastolic blood pressure (RDBP) and resting systolic blood pressure (RSBP) were measured using electronic stop watch, stethoscope and mercury sphygmomano-meter respectively. Exercise modes (continuous and intermittent) were adopted from Sanya and Ajayi (2000) resistant exercises for hemiplegic stroke patients (because of the relationship of DM and cardiovascular disorders such as stroke)

Continuous Exercises-Each subject sat on bicycle ergometer and pedaled the bicycle ergometer at a constant speed of 25 revolutions per minute for five minutes, with a constant resistant of 75 watts (Sanya and Ajayi, 2000).

Intermittent Exercises-Each subject pedaled bicycle ergometer at a constant speed of 50 revolutions per minute for 30 seconds interspersed with 30 seconds of rest period giving a total duration of 5 minutes at a constant wheel resistant of 75 watts (Sanya and Ajayi, 
2000). The heart rates and blood pressures were measured after each experimental protocols.

\section{Data Analysis}

Inferential statistics was used to analyse the physical characteristics of the subjects. Student t-test was employed to analyse pre and post exercise cardiovascular parameters of the subjects in each group while ANOVA was used to find out the differences between the groups.

\section{RESULTS}

Twenty (20) subjects participated in the study with 10 subjects in each group. Student-t test showed no statistical significant differences in the subjects' height ( $\mathrm{t}=0.9 ; \mathrm{p}>0.05)$, weight $(t=0.55 ; \mathrm{p}>0.05)$ and age $(\mathrm{t}=0.064 ; \mathrm{p}>0.05)$ of both groups (table 1)
Analysis of pre and post cardiovascular response within the continuous exercise group showed that there was statistical significant difference in the subjects' heart rates $(\mathrm{t}=8.583 ; \mathrm{p}<0.05)$ but no statistical significant differences for SBP $(\mathrm{t}=0.224 ; \mathrm{p}>0.05)$ and DBP $(\mathrm{t}=0.001 ; \mathrm{p}<0.05)$ (table 2). In addition, pre and post cardiovascular response analysis within the intermittent exercise group showed significant differences in the subjects heart rates $(\mathrm{t}=13.769 ; \mathrm{p}<0.05)$ and SBP $(\mathrm{t}=2.53 ; \mathrm{p}>0.05)$ but no statistical significant difference was found in the subjects DBP $(t=1.19 ; \mathrm{p}>0.05)$ (table 3$)$. Cross comparison of the pre and post exercise parameters between the two groups shows significant differences in HRs of the two groups $(\mathrm{F}=25.932, \mathrm{p}<0$. 05), but no significant difference in their SBPs $(F=0.710$, $\mathrm{P}>0.05)$ and DBPs $(\mathrm{F}=1.397, \mathrm{P}>0.05)$ (table 4).

Table 1: Physical Characteristics of the subjects.

\begin{tabular}{llllll}
\hline & $\begin{array}{l}\text { Continuous } \\
\text { Exercise } \\
\mathbf{n = 1 0}\end{array}$ & $\begin{array}{l}\text { Intermittent } \\
\text { Exercise } \\
\mathbf{n = 1 0}\end{array}$ & df & $\mathbf{t}$ & $\mathbf{p}$ \\
\hline Age(yr) & $1.623 \pm 8.536$ & $1.662 \pm 6.268$ & 9 & -0.9 & $>0.05$ \\
Weight(kg) & $69.200 \pm 6.070$ & $78.4 \pm 10.168$ & 9 & 0.055 & $>0.05$ \\
Height(ht) & $48.9 \pm 7.950$ & $48.7 \pm 5.72$ & 9 & 0.064 & $>0.05$ \\
\hline
\end{tabular}

\section{Remarks}

Age - Not significant

Weight — Not significant

Height — Not significant

Table 2: Comparison of Pre and Post Cardiovascular Responses of Continuous Exercise Group.

\begin{tabular}{llllll}
\hline $\begin{array}{l}\text { Continuous } \\
\text { Exercise }\end{array}$ & $\begin{array}{l}\text { Pre-exercise } \\
\pm \text { SD }\end{array}$ & $\begin{array}{l}\text { Post-exercise } \\
\pm \text { SD }\end{array}$ & $\begin{array}{l}\text { Calculated } \\
\mathbf{t}\end{array}$ & $\begin{array}{l}\text { Critical } \\
\mathbf{t}\end{array}$ & $\mathbf{p}$ \\
\hline HR & $72.6 \pm 10.113$ & $91.2 \pm 7.436$ & 8.583 & 1.833 & $<0.05$ \\
SBP & $133.0 \pm 7.881$ & $133.8 \pm 13.79$ & 0.224 & $>0.05$ & \\
DBP & $82.5 \pm 6.37$ & $82.5 \pm 6.37$ & 0.000 & $>0.05$ & \\
\hline
\end{tabular}

Key:

HR- Heart Rate

SBP- Systolic Blood Pressure

DPB- Diastolic Blood Pressure

Remarks:

HR- Significant

SBP- not significant

DBP- not significant

Table 3: Comparison of Pre and Post Cardiovascular responses of the Intermittent Group.

\begin{tabular}{llllll}
\hline $\begin{array}{l}\text { Intermittent } \\
\text { Group }\end{array}$ & $\begin{array}{l}\text { Pre-Exercise } \\
\mathbf{x} \pm \text { SD }\end{array}$ & $\begin{array}{c}\text { Post-Exercise } \\
\mathbf{x} \pm \text { SD }\end{array}$ & $\begin{array}{c}\text { Calculated } \\
\mathbf{t}\end{array}$ & $\begin{array}{c}\text { Critical } \\
\mathbf{t}\end{array}$ & $\mathbf{p}$ \\
\hline HR & $71.4 \pm 8.996$ & $98.4 \pm 6.518$ & 13.769 & 1.833 & $<0.05$ \\
SBP & $127.5 \pm 13.176$ & $134.0 \pm 10.435$ & 2.55 & - & $<0.05$ \\
DBP & $71.80 \pm 24.064$ & $80.2 \pm 8.997$ & 1.19 & - & $>0.05$ \\
Key: & & Remarks: & \\
HR- Heart Rate & & HR- Significant \\
SBP- Systolic Blood Pressure & & SBP- Significant \\
DBP-Diastolic Blood Pressure & & DBP- not significant & \\
& & &
\end{tabular}


Table 4: Cross Comparison of Pre and Post HR, SBP and DBP for both Continuous and Intermittent Exercise Groups.

\begin{tabular}{llllllll}
\hline & & SS & df & ms & f & sig & p \\
\hline HR & $\begin{array}{l}\text { Between } \\
\text { Groups } \\
\text { Within }\end{array}$ & 5464.80 & 3 & 1821.60 & 25.932 & 0.000 & $<0.05$ \\
SBP & $\begin{array}{l}\text { Groups } \\
\text { Between } \\
\text { Groups }\end{array}$ & 2828.80 & 36 & 70.244 & & & \\
& $\begin{array}{l}\text { Within } \\
\text { Groups } \\
\text { Between } \\
\text { Groups }\end{array}$ & 4814.100 & 36 & 133.725 & & & \\
& 775.30 & 3 & 258.433 & 1.397 & 0.260 & $>0.05$ \\
& $\begin{array}{l}\text { Within } \\
\text { Groups }\end{array}$ & 6660.20 & 36 & 185.006 & & & \\
\hline
\end{tabular}

Remarks:

HR- Significant

SBP- not significant

DBP- not significant

\section{DISCUSSION}

This study was carried out to evaluate the acute cardiorespiratory responses of type 2 diabetes mellitus subjects to continuous and intermittent exercises. The physical characteristics of the subjects in the two groups were similar. However, following the therapeutic exercise, it was observed that there was a significant increase in heart rate (HR) and systolic blood pressure SBP in intermittent group. Similarly, there was an increase in HR but no increase in SBP and DBP in continuous exercise group. The increase in SBP in intermittent exercise group might be due to the fact that during a transition from rest to work, there may be a momentary fall in arterial blood pressure, lasting for a few seconds, which is followed by a steady increase SBP, which reaches its maximum within the first minute, this maximum is proportional to the intensity of the work (Morehouse and Miller, 1971). In addition, any mode of exercise would alter the heart rate due to an increase in blood flow per unit time in rhythmically contracting muscle with a corresponding increase in cardiac output (Morehouse and Miller, 1971). This may be the reason why there was increase in HR of both in intermittent and continuous exercise groups post acute bout of exercises. HR is being used to prescribe the dosage and monitor the intensity of exercise for subjects either for fitness or glycaemic control.

Cross comparison of pre and post HR, SBP and DBP of both groups showed an increase in HR of the two groups but the SBP and DBP did not increase or change. This is in-line with the assertion of Morehouse and Miller (1971).
Demaria et al (1989) also observed a significant increase HR of postmenopausal type 2 diabetic women following 10 minutes acute bout of continuous exercise.

Our present study also showed that intermittent mode of exercise elicited higher cardiovascular responses in type 2 diabetes mellitus subjects. This is in line with the study conducted by Sanya and Ajayi (2000), though on hemiplegic's subjects in which they observed that graded and intermittent exercises elicited higher cardiovascular responses than continuous mode of exercise.

\section{CONCLUSION AND RECOMMENDATIONS}

It was observed from this study that cardiovascular responses of subjects in the intermittent group were higher than that of continuous exercise group. Therefore, we recommend that

1. Continuous exercise should be administered to type 2 diabetes mellitus subjects who want to engage in aerobic exercise either for glycemic control or for cardiorespiratory fitness this is because its low cardiovascular effects.

2. This study is limited because of the small sample size that participated in each of the exercise group and there was no continuity of exercise intervention. We therefore recommend further studies in which large sample size will be incorporated into the study. 


\section{REFERENCES}

- Canadian Diabetes Association (2006). http//www.diabetes.ca/section_About/timeline.as p.Assessed February,14 ${ }^{\text {th }}, 2006$.

- Cotran, R.S., Kumar, Y and Robins, S.L. (1999). Basic Pathology. Saunders: Thomson Press.

- Defronzo, R.A., and Ferrannini, E (2001). Insulin Resistance: A multifaceted Syndrome responsible for NIDDM, Obesity, Hypertension, Dyslipidaemia and Atherosclerotic Cardiovascular Disease. Diabetes Care. 14: 173194.

- Demaria, A., Weymann, A.and Sahn, D.J. (1989). Cardiorespiratory fitness in type 2 diabetes women following continuous exercise session. Circulation. 58 (1072-1083).

- Dunstan, D., Zimmet, P. and Welborn, T. (2001). Diabetes and associated disorders in Australia ; Australian, Obesity and Lifestyle (Ausdiab). Melbourne: International Diabetes Institute Press.

- Erick T., Herfindal, C. and Dick, R.G. (1996). Textbook of Therapeutic Drugs and Disease Management ( $6^{\text {th }}$ Ed) U.S.A: Baltimore Press.

- Expert Committee on the Diagnosis and Classification of Diabetes Mellitus (1997). A report of the Expert Committee on the diagnosis and classification of diabetes mellitus. Diabetes Care 20: 1183-1197.

- Haslet, C., Chilvers, E.R., Hunters, J.A and Boon, N.A. (2002) Davidson's Principle and Practice of Medicine (19 $19^{\text {th }}$ ed) Edinburgh : Churchill Livingstone.

- Hickey, M.S., Carey, J.O., Azevedo J.L et al (1995). Skeletal Muscle fiber composition is related to adiposity and in vitro glucose transport rate in humans. Am. J. Physol. 268(3pt 1): E453E457.

- Hu,F.B., Manson, J.E., Stampfer, M.J., Colditz, G., Li S, Solomon, C.G. and Willet, W.C. (2001). Diet, Lifestyle and risk of type 2 Diabetes Mellitus in Women. N. Engl $J$ Med. 345: 790-797.

- Ivy, J.L., Zderic, T.W and Fogt, D.L (1999).Prevention and Treatment of Diabetes Mellitus. Philadelphia : Lea and Febiger.
- Joslin, E.O., Root, E.F and White, P. (1959). The treatment of Diabetes Mellitus. Philadelphia : Lea and Febiger.

- Kannel, W.B. and McGee, D. (1979). Diabetes and

Cardiovascular Disease: The Framingham Study. JAMA;

241: 2035-2039.

- Leon, A.S. and Sanchez O.A. (2001). Response of blood lipids to exercise training alone or combined with dietary intervention. Med Sci Sports Exerc. 33: S502-S515.

- Morehouse, L.E. and Miller, A.T. (1976). Circulation adjustment in Exercise in Physiology of Exercise (7th Ed) CV Mosby pgs 67-79.

- Prevalence of Diabetes available at: http://www.globeafrica.com/Health/dbstats.htm. Assessed March 23rd, 2004.

- Sanya, A.O. and Ajayi,S.O. Cardiorespiratory responses of Hemiplegics and Normal subjects to Continuous, Intermittent and Graded exercises. Nigerian Medical Journal. 3(1) 6-10.

- Sigal, R.J. and Kenny, G.P. (2003). Physical Activity and Diabetes: CDA Clinical Guidelines Expert Committee. Clinical Practice Guidelines S24-S26.

- Sigal, R.J., Wasserman D.H and CastanedaSceppa, C (2004). Physical Activity /Exercise and Type 2 Diabetes. Diabetes Care 27: 25182539.

- Stewart, K.J., (2002). Exercise training and Cardiovascular Consequences of type 2 diabetes and hypertension: Plausible Mechanism for improving cardiovascular health. JAMA: 288(1622-1631).

- Whelton, S.P., Chin A, Xin X and He J(2002). Effects of aerobic exercise on blood pressure: A Meta analysis of randomized, controlled trials. Ann Intern Med. 136: 493-503.

- Wilmore, J.H. and Costill, D.L. (2004). Physiology of Sports and Exercise (3rd Ed) Illinois , Human Kinetics. 